\title{
Physicians' recommendations to their patients concerning a novel pandemic vaccine: a cross-sectional survey of the 2009 influenza $\mathrm{A} / \mathrm{H} 1 \mathrm{N1}$ pandemic in Japan
}

\author{
Yusuke Inoue $\cdot$ Kenji Matsui
}

Received: 14 October 2010/Accepted: 26 November 2010/Published online: 25 December 2010

(C) The Japanese Society for Hygiene 2010

\begin{abstract}
Objectives Striking a balance between the rapid availability of a novel vaccine while ensuring its safety, quality, and efficacy is a major challenge during a pandemic. We aimed to elucidate physicians' attitudes regarding the novel vaccine during the influenza A/H1N1 pandemic of 2009, and to determine factors that affected their vaccination recommendations to patients.

Methods Of a random sample of 1,000 general practitioners (GPs) in Japan, 515 participated in the cross-sectional anonymous survey conducted just before the novel vaccine was available (between 28 September and 18 October 2009).

Results A total of 453 GPs (88.3\%) replied that they intended to receive the new vaccine themselves; however, only 177 GPs (34.6\%) intended to proactively recommend it to their patients. The anticipated cost of the vaccine negatively influenced the intention to vaccinate themselves and their recommendations to patients $\left(P<0.001, \chi^{2}\right.$ test $)$. Results of multivariate logistic regression analysis showed that physicians with experience in influenza $\mathrm{A} / \mathrm{H} 1 \mathrm{~N} 1$ patient contacts $[1-20$ contacts, odds ratio $(\mathrm{OR})=7.49$ (95\% confidence interval $[\mathrm{CI}]: 1.73-32.36), P=0.007$; $>20$ contacts, $\quad \mathrm{OR}=8.03 \quad(95 \% \quad$ CI: $1.77-36.50)$, $P=0.007$, compared with no contacts] were more likely to recommend the vaccine to patients, whereas those with
\end{abstract}

\footnotetext{
Y. Inoue $(\square)$

Department of Public Policy, Institute of Medical Science,

The University of Tokyo, 4-6-1 Shirokanedai,

Minato-ku, Tokyo 103-8639, Japan

e-mail: yinoue-kyt@umin.ac.jp

K. Matsui

Center for Clinical Bioethics, University of Toyama,

Toyama, Japan
}

knowledge of the fear on the causal association between Guillain-Barré syndrome (GBS) cases and the 1976 swine flu vaccination in the USA were less likely to recommend the vaccine $[\mathrm{OR}=0.66$ (95\% CI: $0.45-0.97), P=0.036]$. Conclusions Results of our survey indicate that physicians experience a moral conflict regarding recommending the novel vaccine to patients, which may be the result of their own experience with the disease, knowledge of vaccine side-effects, and cost.

Keywords Vaccine Pandemic Professional advice . Safety $\cdot$ Cost

\section{Introduction}

One year has passed since epidemiology experts began tracking the $2009 \mathrm{~A} / \mathrm{H} 1 \mathrm{~N} 1$ swine flu pandemic. Now that the influenza $A / H 1 N 1$ seems to have peaked and the emergency has faded, the World Health Organization (WHO) and individual governments have begun to dissect their responses.

One of the major characteristics of the 2009 influenza $\mathrm{A} / \mathrm{H} 1 \mathrm{~N} 1$ was the difficulty in defining the nature of the pandemic itself. During early stages of the outbreak, epidemiologic information on the influenza was mixed, suggesting severe disease in Mexico [1] and relatively mild cases everywhere else [2]. For many countries, this situation was quite different from past pandemic preparations, which planned for the worst-case scenario: an epidemic of severe disease infecting many people. The uncertainty about this novel flu was reflected in confusion concerning the WHO definition of "pandemic" when they declared the H1N1 flu outbreak to be a pandemic on 11 June 2009. For years, the WHO had defined pandemics as outbreaks causing 
"enormous numbers of deaths and illness" [3], but in early May 2009, they removed this phrase from the definition [4].

This situation made planning vaccination programs difficult. Usually public health officials must strike a balance between rapid availability of the vaccine, its safety, quality, and efficacy, and the benefit of vaccination [5]. However, the safety and efficacy of a novel antipandemic vaccine are generally not known before or immediately after its introduction; for example, in 1976, about 10 persons per million vaccinated against swine flu developed Guillain-Barré syndrome, which became a subject of political discussion and ended the vaccination campaign [6, 7]. Neustadt and Fineberg, who were directed by the US Secretary of Health, Education, and Welfare to review the vaccination campaign, described influenza as "a slippery disease" and pointed out five features of influenza-the changing character of the virus, difficulties in predicting vaccine effectiveness, misunderstanding of influenza symptoms, identical symptoms caused by other viruses, and flu-like illnesses - that make a vaccination campaign against a pandemic difficult [8].

These issues may be pressing concerns for physicians deciding whether to recommend a novel pandemic vaccine to their patients. Studies have shown that patients deciding whether to receive the seasonal influenza vaccine are influenced by their physicians [9, 10], demonstrating the importance of physicians' recommendations regarding vaccination. Patients' knowledge regarding the nature of the pandemic and the novel vaccine would be especially limited. Sheather noted that difficulties in assessing the pandemic and the medical utility of a novel pandemic vaccine may result in a moral dilemma for the physician [11]. The moral duty to disclose the risks of vaccination, possibly increasing the patient's unwillingness to be vaccinated, could conflict with the moral duty to achieve population immunity through vaccination [12].

Results of surveys of physicians' attitudes regarding the 2009 influenza A/H1N1 pandemic novel vaccine have been reported [13-15]; however, these studies primarily investigated physicians' attitudes to their own vaccination. We therefore undertook a cross-sectional survey to investigate the intention of Japanese physicians to be vaccinated as well as their intention to recommend the vaccine to their patients to clarify physicians' attitudes toward such a novel and untested vaccine.

\section{Materials and methods}

Study population

We conducted a questionnaire-based survey of GPs working in clinics in Japan. To survey physicians' attitudes on this novel and untested pandemic influenza $\mathrm{A} / \mathrm{H} 1 \mathrm{~N} 1$ vaccine, the survey was performed between 28 September and 18 October 2009, before the vaccine's introduction. In Japan, a clinic (Shin-ryo-jyo) is defined as a small hospital with fewer than 20 beds (or no beds), providing mainly general, primary, or home-based care. These clinics have been the frontline for treating A/H1N1 influenza patients in Japan. We mailed our survey to a random sample of 1,000 GPs employed at the 101,052 clinics registered by the Welfare and Medical Service Agency. The research protocol was in accordance with the ethical standards in the Declaration of Helsinki, and was reviewed by the Research Ethics Committee of The University of Tokyo Graduate Medical School.

\section{Questionnaire}

A self-administered, anonymous questionnaire was used, and the participants were asked to return the completed questionnaire by mail. The questionnaire included items about (1) demographics (sex, age), (2) medical specialty or department (internal medicine, surgery, or other), (3) number of daily patient contacts, (4) number of 2009 influenza $\mathrm{A} / \mathrm{H} 1 \mathrm{~N} 1$ patient contacts by time of survey, (5) frequency of personal seasonal influenza vaccination (every year, almost every year, rarely, or never), (6) knowledge of the fear on the causal association between Guillain-Barré syndrome (GBS) cases and the 1976 swine flu vaccination in the USA (yes or no) [6]. To determine physicians' attitudes toward vaccination, participants were asked (7) whether they intended to receive the influenza $\mathrm{A} / \mathrm{H} 1 \mathrm{~N} 1$ vaccine themselves (intend or do not intend), and (8) whether they intended to recommend the influenza $\mathrm{A} / \mathrm{H} 1 \mathrm{~N} 1$ vaccination to patients (intend or do not intend). To determine the influence of vaccine cost, participants were asked about (9) their intention to receive the influenza $\mathrm{A} / \mathrm{H} 1 \mathrm{~N} 1$ vaccine themselves if the vaccine cost US \$33-44 - the suggested cost at the time of this survey-(intend or do not intend), and (10) their recommendations to patients if the vaccine cost US \$33-44 (intend or do not intend).

\section{Statistical analysis}

The first analysis, concerning the intention to recommend the vaccine to patients and intention to be vaccinated themselves, evaluated potential related factors (including cost) using the $\chi^{2}$ test. Then, logistic regression analysis was used to evaluate independent predictors of intention to recommend the novel vaccine to patients among physicians who intended to receive the vaccine themselves. Factors that were significant in the univariate analysis (number of A/H1N1 patient contacts by time of survey, knowledge 
about the fears of the 1976 swine flu vaccination in the USA) were included in the multivariate analysis. All statistical analyses were performed using PASW version 18 (SPSS Ltd., Chicago, IL, USA), and $P<0.05$ was considered significant. Unmarked items in the questionnaire and missing data were not included in the analysis. Vaccine costs were estimated using the exchange rate 90 yen $=$ US \$1 (October 2009).

\section{Results}

We received a total of 515 responses (response rate $51.5 \%$ ). Respondent demographics are presented in Table 1. Most GPs were male, older than 40 years, specialized in general internal medicine, and typically treated at least 50 patients per day. Most had a history of regular

Table 1 Respondent characteristics

\begin{tabular}{|c|c|c|}
\hline & $n$ & $\%$ \\
\hline All & 515 & \\
\hline \multicolumn{3}{|l|}{ Sex } \\
\hline Men & 480 & 93.2 \\
\hline Women & 31 & 6.0 \\
\hline Unknown $^{\mathrm{a}}$ & 4 & 0.8 \\
\hline \multicolumn{3}{|l|}{ Age, years } \\
\hline $20-39$ & 18 & 3.5 \\
\hline $40-59$ & 305 & 59.2 \\
\hline$\geq 60$ & 191 & 37.1 \\
\hline Unknown $^{\mathrm{a}}$ & 1 & 0.2 \\
\hline \multicolumn{3}{|l|}{ Department/specialty } \\
\hline Internal medicine & 368 & 71.5 \\
\hline Surgery & 99 & 19.2 \\
\hline Other & 47 & 9.1 \\
\hline Unknown $^{\mathrm{a}}$ & 1 & 0.2 \\
\hline \multicolumn{3}{|l|}{ No. of patients seen per day } \\
\hline$<50$ & 177 & 34.4 \\
\hline$\geq 50$ & 333 & 64.7 \\
\hline Unknown $^{\mathrm{a}}$ & 5 & 1.0 \\
\hline \multicolumn{3}{|c|}{ No. of $\mathrm{A} / \mathrm{H} 1 \mathrm{~N} 1$ patient contacts by time of survey } \\
\hline 0 & 27 & 5.2 \\
\hline $1-20$ & 390 & 57.7 \\
\hline$>20$ & 98 & 36.9 \\
\hline Unknown $^{\mathrm{a}}$ & 1 & 0.2 \\
\hline \multicolumn{3}{|l|}{ Seasonal influenza vaccination } \\
\hline Every year/almost every year & 473 & 91.8 \\
\hline Sometimes/rarely & 41 & 8.0 \\
\hline Unknown $^{\mathrm{a}}$ & 1 & 0.2 \\
\hline
\end{tabular}

${ }^{\mathrm{a}}$ Unmarked items or missing data seasonal vaccination. At the time of the survey, more than $90 \%$ of them answered that they had already treated patients with influenza $\mathrm{A} / \mathrm{H} 1 \mathrm{~N} 1$.

As shown in Table 2, the number of patients seen per day was associated with both intention to recommend the vaccine to patients and intention to be vaccinated. The intention to recommend the vaccine was also associated with the number of $\mathrm{A} / \mathrm{H} 1 \mathrm{~N} 1$ patient contacts by time of survey, whereas the intention to receive the vaccine was associated with the physician's sex, history of seasonal influenza vaccination, and knowledge about the fears of the 1976 swine flu vaccination in the USA. Although 453 physicians $(88.3 \%)$ intended to receive the vaccine themselves, only 177 physicians (34.6\%) intended to recommend vaccination to their patients. This result indicates that factors influencing physicians' attitudes toward recommending the vaccine to patients differed from factors influencing their intention to receive the vaccine themselves.

Cost was also an important factor affecting physicians' attitudes toward the vaccine. When physicians were informed that the vaccine would not be free but would cost US \$33-44, a significant number of physicians reversed their decisions regarding vaccination (Table 3). Among GPs who intended to recommend that patients receive the vaccine if it were free, 56 physicians $(31.6 \%)$ replied that they would not recommend the vaccine at the planned cost. In contrast, only eight physicians who originally intended to be vaccinated changed their decisions because of cost $(1.8 \%)$.

Logistic regression was used to determine factors influencing vaccination recommendations to patients among the 453 physicians who intended to be vaccinated themselves (Table 4). Physicians with knowledge about the fears of the 1976 swine flu vaccination in the USA were less likely to recommend the vaccine to patients, whereas those who had more $\mathrm{A} / \mathrm{H} 1 \mathrm{~N} 1$ patient contacts were more likely to recommend the vaccine. In fact, the more A/H1N1 patient contacts the physicians had, the more likely they were to recommend vaccination: $8.0 \%$ ( 0 patients treated), $36.3 \%$ (1-20 patients treated), $35.7 \%$ ( $>20$ patients treated) (data not shown in the table).

\section{Discussion}

This preliminary survey of GPs' attitudes regarding the novel A/H1N1 vaccine in Japan was conducted before the vaccine itself was available, when the clinical validity, its efficacy and safety in particular, was unclear. Our findings confirmed that Japanese physicians faced a moral conflict regarding recommending the novel vaccine to patients during the pandemic, and their attitudes were influenced by 
Table 2 Physicians' attitudes regarding the novel vaccine against the 2009 pandemic influenza A/H1N1

\begin{tabular}{|c|c|c|c|c|c|c|}
\hline & \multicolumn{3}{|c|}{ Intention to recommend vaccine to patients } & \multicolumn{3}{|c|}{ Intention to receive vaccine } \\
\hline & $\begin{array}{l}\text { Intend } \\
(n=177)\end{array}$ & $\begin{array}{l}\text { Do not intend } \\
(n=334)\end{array}$ & $P^{*}$ & $\begin{array}{l}\text { Intend } \\
(n=453)\end{array}$ & $\begin{array}{l}\text { Do not intend } \\
(n=60)\end{array}$ & $P^{*}$ \\
\hline \multicolumn{7}{|l|}{ Sex } \\
\hline Men & 168 & 309 & 0.334 & $427 *$ & $52^{*}$ & 0.02 \\
\hline Women & 8 & 23 & & $23 *$ & $8^{*}$ & \\
\hline \multicolumn{7}{|l|}{ Age, years } \\
\hline $20-39$ & 5 & 13 & 0.411 & 16 & 2 & 0.751 \\
\hline $40-59$ & 100 & 204 & & 271 & 33 & \\
\hline$\geq 60$ & 73 & 117 & & 166 & 25 & \\
\hline \multicolumn{7}{|l|}{ Department/specialty } \\
\hline Internal medicine & 131 & 235 & 0.595 & 323 & 44 & 0.775 \\
\hline Surgery & 30 & 69 & & 87 & 12 & \\
\hline Other & 16 & 30 & & 43 & 4 & \\
\hline \multicolumn{7}{|l|}{ No. of patients seen per day } \\
\hline$<50$ & 51 & 126 & 0.04 & 149 & 28 & 0.041 \\
\hline$\geq 50$ & 126 & 204 & & 301 & 31 & \\
\hline \multicolumn{7}{|c|}{ No. of $\mathrm{A} / \mathrm{H} 1 \mathrm{~N} 1$ patient contacts by time of survey } \\
\hline 0 & 2 & 25 & 0.009 & 25 & 2 & 0.136 \\
\hline $1-20$ & 140 & 246 & & 347 & 41 & \\
\hline$>20$ & 35 & 63 & & 81 & 17 & \\
\hline \multicolumn{7}{|l|}{ Seasonal influenza vaccination } \\
\hline Every year/almost every year & 168 & 303 & 0.119 & $433 *$ & 39 & $<0.001$ \\
\hline Rarely/never & 9 & 31 & & 20 & 21 & \\
\hline \multicolumn{7}{|c|}{ Knowledge of the 1976 US Guillain-Barré syndrome cases } \\
\hline Yes & 89 & 189 & 0.192 & 198 & 37 & 0.013 \\
\hline No & 88 & 145 & & 255 & 23 & \\
\hline \multicolumn{7}{|l|}{ Intention to receive vaccination } \\
\hline Intend & 172 & 280 & $<0.001$ & - & - & - \\
\hline Do not intend & 5 & 54 & & - & - & - \\
\hline
\end{tabular}

* Differences between "Intend" and "Do not intend" in each group significant at $P<0.05\left(\chi^{2}\right.$ test)

Table 3 Association between the cost of the novel vaccine and physicians' attitudes regarding vaccination against the 2009 pandemic influenza $\mathrm{A} / \mathrm{H} 1 \mathrm{~N} 1$

\begin{tabular}{|c|c|c|c|c|c|c|}
\hline & \multicolumn{3}{|c|}{ Intention to recommend vaccine to patients } & \multicolumn{3}{|c|}{ Intention to be vaccinated } \\
\hline & Intend $(n=177)$ & Do not intend $(n=334)$ & $P^{*}$ & Intend $(n=453)$ & Do not intend $(n=60)$ & $P^{*}$ \\
\hline \multicolumn{7}{|l|}{ If a novel vaccine costs US $\$ 33-40$} \\
\hline Intend (even if it has a cost) & 121 & 19 & $<0.001$ & 445 & 1 & $<0.001$ \\
\hline Do not intend (if it has a cost) & 56 & 315 & & 8 & 59 & \\
\hline
\end{tabular}

* Differences between "Intend" and "Do not intend" in each group significant at $P<0.05$ ( $\chi^{2}$ test)

their personal experience of the pandemic and the economic burden on their patients.

\section{Physicians' recommendation on vaccination}

An approved vaccine typically takes 5-6 months to become available for clinical use, and its safety has often not been fully evaluated before vaccination begins [16]. In August 2009, 2 months after the influenza pandemic declaration by the WHO [17], the Japanese government decided to import this novel vaccine from foreign producers to meet the planned needs for 70 million people, because it was impossible to secure the vaccine in Japan in the short time available [18]. However, some experts 
Table 4 Logistic regression model for intention to recommend the influenza A/H1N1 vaccine to patients

\begin{tabular}{|c|c|c|c|c|c|c|}
\hline & \multicolumn{3}{|c|}{ Univariate analysis } & \multicolumn{3}{|c|}{ Multivariate analysis } \\
\hline & OR & $95 \% \mathrm{CI}$ & $P$ & OR & $95 \% \mathrm{CI}$ & $P$ \\
\hline \multicolumn{7}{|l|}{ Sex } \\
\hline $\operatorname{Men}^{\mathrm{a}}$ & 1 & & & & - & \\
\hline Women & 0.86 & $0.36-2.08$ & 0.738 & & - & \\
\hline \multicolumn{7}{|l|}{ Age, years } \\
\hline $20-39^{\mathrm{a}}$ & 1 & & & & - & \\
\hline $40-59$ & 1.64 & $0.52-5.24$ & 0.399 & & - & \\
\hline$\geq 60$ & 2.32 & $0.72-7.50$ & 0.159 & & - & \\
\hline \multicolumn{7}{|l|}{ Department/specialty } \\
\hline Internal medicine $^{\mathrm{a}}$ & 1 & & & & - & \\
\hline Surgery & 0.77 & $0.47-1.26$ & 0.299 & & - & \\
\hline Other & 0.91 & $0.47-1.76$ & 0.778 & & - & \\
\hline \multicolumn{7}{|l|}{ No. of patients seen per day } \\
\hline$<50^{\mathrm{a}}$ & 1 & & & & - & \\
\hline$\geq 50$ & 0.74 & $0.49-1.11$ & 0.145 & & - & \\
\hline \multicolumn{7}{|c|}{ No. of $\mathrm{A} / \mathrm{H} 1 \mathrm{~N} 1$ patient contacts by time of survey } \\
\hline $0^{\mathrm{a}}$ & 1 & & & 1 & & \\
\hline $1-20$ & 7.45 & $1.73-32.10$ & 0.007 & 7.49 & $1.73-32.36$ & 0.007 \\
\hline$>20$ & 8.32 & $1.84-37.69$ & 0.006 & 8.03 & $1.77-36.50$ & 0.007 \\
\hline \multicolumn{7}{|l|}{ Seasonal influenza vaccination } \\
\hline Rarely/never ${ }^{\mathrm{a}}$ & 1 & & & & - & \\
\hline Every year/almost every year & 0.69 & $0.26-1.82$ & 0.450 & & - & \\
\hline \multicolumn{7}{|c|}{ Knowledge of the past US Guillain-Barré syndrome cases } \\
\hline $\mathrm{No}^{\mathrm{a}}$ & 1 & & & 1 & & \\
\hline Yes & 0.66 & $0.45-0.96$ & 0.031 & 0.66 & $0.45-0.97$ & 0.036 \\
\hline
\end{tabular}

Unmarked or missing data were not included in the analysis

$C I$ confidence interval, $O R$ odds ratio

${ }^{a}$ Reference variable

publicly voiced concerns about the safety of these imported vaccines, because they contained adjuvants not previously tested in Japan [18, 19]. In addition, the idea of a "fasttracked" vaccine led to concerns that the risks of a novel vaccine might outweigh the benefits [20]. The government first considered introducing the novel vaccine without clinical trials, citing existing legal procedures for such emergencies, but decided to test its safety by vaccinating 200 adults and 360 children [21]. However, some experts considered this small trial to be insufficient to eliminate concerns about vaccine safety [18].

The advice of physicians is known to influence people's attitudes regarding vaccination against seasonal influenza [13]. Because the public's understanding of pandemic influenza is more limited than is the case for seasonal influenza, physicians' recommendations are even more important for patients deciding whether to receive a novel vaccine. Supporting physicians' judgments and understanding of vaccination in a pandemic is therefore critically important for vaccination programs.
We did not expect the result showing that many physicians did not intend to recommend the novel vaccine to their patients. This could be considered physician paternalism, because patients may not be aware of the option of vaccination. However, providing information about a novel pandemic vaccine carries moral concerns for physicians, who must strike a balance between the vaccine risk to their patients and the benefits of patient and population immunity. We found that attitudes toward vaccination for patients were associated with their level of experience treating influenza $\mathrm{A} / \mathrm{H} 1 \mathrm{~N} 1$. Although the overwhelming majority of influenza A/H1N1 patients experienced mild illness, this novel influenza exhibited characteristics that differed from those of seasonal influenza or other novel influenzas (a highly contagious nature and the occurrence of severe cases and deaths, especially among teenagers and young adults) [22-24]. It is possible that physicians who actually examined patients were intensely aware of the difficulty of treatment and the need for prevention. Sharing such experiences would be important to advance 
preventive vaccination projects and reduce the prevalence of new infectious diseases.

Our results showed that, even among physicians who intended to be vaccinated themselves, knowledge about the fears of the 1976 swine flu vaccination in the USA reduced the likelihood that they would recommend the novel vaccine to patients. It is possible that the uncertainty of no-fault compensation for vaccine-related injuries contributed to physicians' reluctance to recommend antipandemic vaccination in Japan. Introducing political measures to care for victims of vaccine side-effects, as some countries have done, may be effective in balancing of the risks and benefits, and more physicians might be willing to recommend the novel vaccine to patients [25]. Another reason not to offer information on the novel vaccine might be physicians' fear of liability concerning injury to patients suspected to be due to the vaccine. This point might require us to consider exemption of physicians' liability for conditions possibly related to vaccination.

\section{Issues of cost}

Our study indicated that cost can also affect whether a physician recommends vaccination to patients. Some countries announced that they would cover the entire cost of the novel A/H1N1 vaccine (e.g., USA [26], UK [27], and China [28]). In contrast, the Japanese government officially declared in October that individuals would pay 3,600 yen (US \$40) for the vaccine [29], as planned. How this affected vaccination choice was unknown.

In Japan, there was a program of mass influenza vaccination among schoolchildren, but it was later challenged for its safety and effectiveness and was eventually abandoned in 1994. Subsequently, influenza vaccines have been offered without charge only to the elderly population, under the revised Preventative Vaccination Law (no. 51, 1994). In 2007, $54.7 \%$ of the eligible elderly population received the influenza vaccine [30]. Official vaccination rates for younger age groups are not available, but are widely thought to be much lower. Introducing a mass vaccination program into a population with little related experience may prove to be difficult in Japan.

While the cost of the novel A/H1N1 vaccine considered in this study is nearly identical to that of the seasonal influenza vaccination in Japan, most Japanese people are not used to receiving vaccinations and may perceive this expense as burdensome. A study in another country concerning vaccination for seasonal influenza has reported cost to be a negative factor [31]. Therefore, even if a vaccine were shown to be effective, the cost may negatively influence patients' intention to receive the vaccine, as well as physicians' intention to recommend the vaccine to their patients.

Strengths and weaknesses of the study

Previous research has examined only the intention of subjects deciding whether to receive the novel vaccine themselves [13, 32]. No empirical data exist demonstrating how physicians' attitudes regarding their own vaccination affect their advice to patients. Because this is the first study to assess the influence of personal intention on decisionmaking for others regarding the $\mathrm{A} / \mathrm{H} 1 \mathrm{~N} 1$ vaccination, these results are likely to be useful in the development of vaccination policy.

An important limitation of the present study is the small sample size. In addition, we documented only physicians' intentions, which may not reflect actual vaccination rates. However, to understand the concerns of physicians and society as a whole, and to exclude effects of education about the vaccine after its introduction, it was necessary to conduct the survey within a brief period before the vaccine's implementation. Thus, our sample of 1,000 physicians was relatively large given the restricted time. In the future, we need to assess changes in attitude after implementation begins. Second, although the age distribution of GP respondents was similar to the national age distribution $\left(P>0.05, \chi^{2}\right.$ test $)$, the percentage of female GP respondents $(6.0 \%)$ was lower than the national average $(15.5 \%)$ [33]. This may have skewed the results; however, sex has not been reported to be associated with physicians' attitudes toward vaccination in other studies.

\section{Conclusions}

Our results may demonstrate that physician decisionmaking regarding vaccination during a "mild pandemic" may be based, in part, on the physicians' personal experiences or the patients' economic burden when the nature of a pandemic and the vaccine are not established. Infectious disease cannot be prevented solely by physicians or by the public; prevention can only occur through their interactions. To better characterize these interactions, additional study of the factors that affect physicians' attitudes toward their recommendations and presentation of information to patients during a pandemic is warranted.

Acknowledgments We thank Prof. Akira Akabayashi, Mr. Satoru Yoshie, and Dr. Hitoshi Arima of The University of Tokyo for their invaluable advice. We also thank Dr. Shoichi Maeda of Keio University and Ms. Etsuko Kamishiraki of Kochi Women's University for their important contributions to the questionnaire and its dissemination. 


\section{References}

1. Charatan F. UN warns that swine flu outbreak could turn into pandemic. BMJ. 2009;338:b1751.

2. European Centre for Disease Prevention and Control. ECDC situation update on (A H1N1) influenza pandemic. 2009. http://www.ecdc.europa.eu/en/aboutus/organisation/Director\%20 Speeches/0912_DS_ZJ_Situation_Update_on_Influenza_Pandemic. pdf. Accessed 30 Sept 2010.

3. Doshi P. Calibrated response to emerging infections. BMJ. 2009;339:b3471.

4. Cohen E. When a pandemic isn't a pandemic. CNN. 2009. http://edition.cnn.com/2009/HEALTH/05/04/swine.flu.pandemic/ index.html. Accessed 30 Sept 2010.

5. Wood JM. Developing vaccines against pandemic influenza. Philos Trans R Soc Lond B Biol Sci. 2001;356:1953-60.

6. Marks JS, Halpin TJ. Guillain-Barré syndrome in recipients of A/New Jersey influenza vaccine. JAMA. 1980;243:2490-4.

7. World Health Organization. Safety of pandemic (H1N1) 2009 vaccines. 2009. http://www.who.int/csr/disease/swineflu/frequently_ asked_questions/vaccine_preparedness/safety_approval/en/index. html. Accessed 30 Sept 2010.

8. Neustadt RE, Fineberg HV. The swine flu affair. Honolulu: University Press of the Pacific; 2005.

9. Daley MF, Crane LA, Chandramouli V, Beaty BL, Barrow J, Allred N, et al. Influenza among healthy young children: changes in parental attitudes and predictors for immunization during the 2003 to 2004 influenza season. Pediatrics. 2006;117:e268-77.

10. Nowalk MP, Lin CJ, Zimmerman RK, Ko FS, Hoberman A, Zoffel L, et al. Changes in parents' perceptions of infant influenza vaccination over two years. J Natl Med Assoc. 2007;99:636-41.

11. Sheather J. Ethics in the face of uncertainty: preparing for pandemic flu. Clin Ethics. 2006;1:224-7.

12. British Medical Association Ethics Department. Public health dimensions of medical practice. In: British Medical Association, editor. Medical ethics today. 2nd ed. London: BMJ Publishing Group; 2004. p. 703-34.

13. Chor JS, Ngai KL, Goggins WB, Wong MC, Wong SY, Lee N, et al. Willingness of Hong Kong healthcare workers to accept pre-pandemic influenza vaccination at different WHO alert levels: two questionnaire surveys. BMJ. 2009;339:b3391.

14. Lautenbach E, Saint S, Henderson DK, Harris AD. Initial response of health care institutions to emergence of H1N1 influenza: experiences, obstacles, and perceived future needs. Clin Infect Dis. 2010;50:523-7.

15. Rachiotis G, Mouchtouri VA, Kremastinou J, Gourgoulianis K, Hadjichristodoulou C. Low acceptance of vaccination against the 2009 pandemic influenza $\mathrm{A}(\mathrm{H} 1 \mathrm{~N} 1)$ among healthcare workers in Greece. Euro Surveill. 2010;15:pii19486. http://edition.cnn.com/ 2009/HEALTH/05/04/swine.flu.pandemic/index.html. Accessed 30 Sept 2010.

16. World Health Organization. Pandemic influenza vaccine manufacturing process and timeline. Pandemic (H1N1) 2009 briefing note 7. 2009. http://www.who.int/csr/disease/swineflu/notes/ h1n1_vaccine_20090806/en/index.html. Accessed 30 Sept 2010.

17. Chan M. World now at the start of 2009 influenza pandemic. Statement to the press by World Health Organization DirectorGeneral. 2009. http://www.who.int/mediacentre/news/statements/ 2009/h1n1_pandemic_phase6_20090611/en/index.html. Accessed 30 Sept 2010.
18. Ministry of Health, Labour and Welfare of Japan. Informal meeting on the novel influenza vaccine. 2009 (in Japanese). http://www.mhlw.go.jp/bunya/kenkou/kekkaku-kansenshou04/ pdf/090907_01.pdf. Accessed 30 Sept 2010.

19. Ministry of Health, Labour and Welfare of Japan. The first shipping of the A/H1N1 influenza vaccine (in Japanese). 2009. http://www.mhlw.go.jp/kinkyu/kenkou/influenza/houdou/2009/ 10/dl/infuh1006-04.pdf. Accessed 30 Sept 2010.

20. World Health Organization. Safety of pandemic vaccines, Pandemic (H1N1) 2009 briefing note 6. 2009. http://www.who.

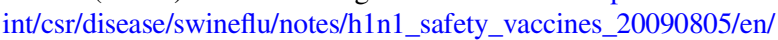
index.html. Accessed 30 Sept 2010.

21. Ministry of Health, Labour and Welfare of Japan. The interim report on the clinical trial of the novel A/H1N1 vaccine (in Japanese). 2009. http://www.mhlw.go.jp/kinkyu/kenkou/influenza/dl/ infu091016-01.pdf. Accessed 30 Sept 2010.

22. World Health Organization. WHO recommendations on pandemic (H1N1) 2009 vaccines, Pandemic (H1N1) 2009 briefing note 2. 2009. http://www.who.int/csr/disease/swineflu/notes/h1n1_vaccine_20090 713/en/index.html. Accessed 30 Sept 2010.

23. World Health Organization. Preparing for the second wave: lessons from current outbreaks. Pandemic (H1N1) 2009 briefing note 9. 2009. http://www.who.int/csr/disease/swineflu/notes/h1n1_second_ wave_20090828/en/index.html. Accessed 30 Sept 2010.

24. World Health Organization. Experts advise WHO on pandemic vaccine policies and strategies. Pandemic (H1N1) 2009 briefing note 14. 2009. http://www.who.int/csr/disease/swineflu/notes/briefing 20091030/en/index.html. Accessed 30 Sept 2010.

25. Evans G. Vaccine injury compensation programs worldwide. Vaccine. 1999;17(suppl 3):S25-35.

26. Centers for Disease Control and Prevention. Questions and answers on 2009 H1N1 vaccine financing. 2009. http://www.cdc.gov/ H1N1flu/vaccination/statelocal/vaccine_financing.htm. Accessed 30 Sept 2010.

27. National Health Service. Information on the swine flu vaccine. 2009. http://www.nhs.uk/conditions/pandemic-flu/pages/vaccine.aspx.

28. Xinhua News Agency. Beijing starts free A/H1N1 flu vaccination. 2009. http://news.xinhuanet.com/english/2009-10/21/content_1229 0207.htm. Accessed 30 Sept 2010.

29. Ministry of Health, Labour and Welfare of Japan. Novel influenza vaccination: what you have to know and understand (administration briefers) (in Japanese). 2009. http://www.mhlw.go.jp/bunya/ kenkou/kekkaku-kansenshou04/pdf/p091022-1.pdf. Accessed 30 Sept 2010.

30. Ministry of Health, Labour and Welfare of Japan. The task force on vaccine demand: The demand of vaccine in 2007 (in Japanese). 2008. http://www.mhlw.go.jp/shingi/2008/06/d1/s0618-9d.pdf. Accessed 30 Sept 2010.

31. Nexøe J, Kragstrup J, Rønne T. Impact of postal invitations and user fee on influenza vaccination rates among the elderly. A randomized controlled trial in general practice. Scand J Prim Health Care. 1997;15:109-12.

32. Seale H, McLaws ML, Heywood AE, Ward KF, Lowbridge CP, Van D, et al. The community's attitude towards swine flu and pandemic influenza. Med J Aust. 2009;191:267-9.

33. Statistics and Information Department, Minister's Secretariat, Ministry of Health, Labour and Welfare of Japan. The biyearly report on the general situation of medical practitioners, dentists, and pharmacists. (in Japanese). 2006. http://www.mhlw.go.jp/ toukei/saikin/hw/ishi/06/index.html. Accessed 30 Sept 2010. 